Georgetown University Law Center

Scholarship @ GEORGETOWN LAW

2008

\title{
Climate Change, Intergenerational Equity, and International Law
}

Edith Brown Weiss

Georgetown University Law Center, weiss@law.georgetown.edu

This paper can be downloaded free of charge from:

https://scholarship.law.georgetown.edu/facpub/1625

http://ssrn.com/abstract=2734420

9 Vt. J. Envtl. L. 615-627 (2008)

This open-access article is brought to you by the Georgetown Law Library. Posted with permission of the author. Follow this and additional works at: https://scholarship.law.georgetown.edu/facpub

Part of the Environmental Law Commons, and the International Law Commons 


\section{Climate Change, InTERgenerational Equity, AND INTERNATIONAL LAW ${ }^{\dagger}$}

\section{Edith Brown Weiss*}

\section{INTRODUCTION}

Climate change is an inherently intergenerational problem with extremely serious implications for equity between ourselves and future generations and among communities in the present and the future. More than twenty years ago I wrote an article entitled Climate Change, Intergenerational Equity and International Law. The basic issues and the analysis remain the same, though a number of international agreements relevant to climate change have been concluded since then.

At the time the Article was drafted, there was still considerable scientific uncertainty as to whether global warming was occurring, when it would occur, and with what effects within geographic regions. In an effort to address these uncertainties, the United Nations Environment Programme, the World Meteorological Organization, and the International Council of Scientific Unions jointly held the First World Climate Conference in 1979. Other international meetings focused on climate and carbon dioxide followed, culminating in a meeting of experts in 1985 in Villach, Austria, where an international consensus was achieved for the first time on the importance of the problem. The Article reprinted here was prepared as a Background Paper for the Villach Conference (Villach Article).

Three years later, in 1988, thirty-five countries founded the Intergovernmental Panel on Climate Change (IPCC), which produced its First Assessment of climate change and its effects in 1991. The IPCC is the most far-reaching international effort to ensure that authoritative scientific

$\dagger^{\prime}$ The Vermont Journal of Envimonmental Law is reprinting this Article, which was originally published by Transnational Publishers, Inc., as Appendix D in EDITH BROWN WEISS, IN FAIRNESS tO FUTURE GENERATIONS: INTERNATIONAL LAW, COMMON PATRIMONY, AND INTERGENERATIONAL EQUITY 345-51 (1989). The introduction for this reprinted edition has been newly added by the author.

* Francis Cabell Brown Professor of Intemational Law, Georgetown University School of Law, A.B., Stanford University; J.D., Harvard Law School; Ph.D., University of California (Berkeley); LL.D.(Hon.), Chicago-Kent College of Law, Illinois Institute of Technology. 
assessments are placed before the international community. In 2007, the IPCC produced its Fourth, and most recent, Assessment. The IPCC concluded that " $[\mathrm{w}]$ arming of the climate system is unequivocal, as is now evident from observations of increases in global average air and ocean temperatures, widespread melting of snow and ice, and rising global average sea level." It further concluded that "[m]ost of the observed increase in globally-averaged temperatures since the mid-20th century is very likely due to the observed increase in anthropogenic GHG [Green House Gas] concentrations."2

The impacts from warming are predicted to be long-term, widespread, and severe. Even if a few countries may experience more favorable local climate in the near term, they are likely to suffer in the long term because of potentially devastating consequences elsewhere that will affect their own economic and social conditions. Developing countries will very likely suffer the worst effects from climate change because they have the least resilience and capacity to adapt.

No longer can we ignore the fact that climate change is an intergenerational problem and that the well-being of future generations depends upon actions that we take today. The Villach Article was included as an appendix to the 1989 book In Fairness to Future Generations. This book defines a theory of intergenerational equity, proposes principles of intergenerational equity, and sets forth both rights and obligations of future generations for the robustness and integrity of the Earth and its natural resources and for cultural resources.

The basic concept is that all generations are partners caring for and using the Earth. Every generation needs to pass the Earth and our natural and cultural resources on in at least as good condition as we received them. This leads to three principles of intergenerational equity: options, quality, and access. The first, comparable options, means conserving the diversity of the natural resource base so that future generations can use it to satisfy their own values. The second principle, comparable quality, means ensuring the quality of the environment on balance is comparable between generations. The third one, comparable access, means non-discriminatory access among generations to the Earth and its resources.

These principles satisfy the basic criteria of balance, flexibility, cultural acceptability, and clarity. One criterion is to balance the needs of future

1. U.N. Env't Programme and World Meteorological Org., Intergovernmental Panel on Climate Change [PCC], IPCC Fourth Assessment Report, Climate Change 2007: The Physical Science Basis (Summary for Policymakers) 5 (Susan Solomon et al. eds., 2007), available at http://ipccwgl .ucar.edu/wg1/ Report/AR4WG1_Print_SPM.pdf (contribution of Working Group I).

2. Id. at 10 (citation omitted). 
generations with those of the present, neither licensing the present generation to consume without attention to the interests of future generations or requiring it to sacrifice unreasonably to meet indeterminate future needs. Since we cannot predict the values of future generations, we also have to provide them with the options and quality to satisfy their own values and needs. In addition, the principles need to be generally acceptable to the many different cultures in the world, and finally they have to be reasonably clear so that they can be implemented and applied.

Despite subsequent relevant legal developments, the intergenerational issues raised in the Villach Article remain. In 1985, States concluded a framework agreement to protect the ozone layer, The Vienna Convention for the Protection of the Ozone Layer, and two years later the Montreal Protocol on Substances that Deplete the Ozone Layer. Some of the chemicals controlled in this Protocol also are greenhouse gases, and the Protocol has made a useful contribution to limiting these greenhouse gas emissions.

In 1992, after eighteen months of negotiation, countries finalized the United Nations Framework Convention on Climate Change and opened it for signature at the Rio Conference on Environment and Development. Notably, the Convention does not contain explicit targets and timetables for stabilizing atmospheric concentrations of greenhouse gases. However, it does obligate States party to provide national inventories of sources and sinks of greenhouse gases, regular national reports on policies, and measures that limit emissions of greenhouse gases and enhance the sinks for them. As of April 1, 2008, 192 countries are parties to the Convention.

At the first meeting of the Conference of the Parties to the UNFCC, countries agreed to a mandate to negotiate a new binding instrument to apply to the period beyond the year 2000 and to consider quantified targets and timetables for controlling greenhouse gas emissions. The Kyoto Protocol to the Convention was concluded in 1997, although it entered into force only in 2005. As of January 15, 2008, 178 countries are parties to the Protocol, but not the United States. The Kyoto Protocol has had only limited effect. States are now looking to negotiate new arrangements to govern the post-Kyoto commitment period, which ends in 2012.

Recently, systems for trading in greenhouse gas emissions as a means to control emissions have emerged in Europe and North America. These include the European Union Emissions Trading Scheme (EU ETS), the voluntary U.S.-based Chicago Climate Exchange (CCX), the Chicago Climate Futures Exchange (CCFE), and a new Montréal Climate Exchange (MCeX). The last is a joint venture of the Montréal Exchange (MX) and 
the Chicago Climate Exchange, which is expected to be launched at the end of May 2008.

The Villach Article refers to international environmental agreements in other areas. In the past twenty years, there have been significant developments in agreements to control pollution and protect ecosystems in regional seas, in the marine environment, in the atmosphere, and in fresh water. Indeed as of 2000 , there were well over 1000 international legal instruments that were either partially or fully concerned with protection of the environment. Many more have been added since then. But despite these developments, we do not yet have international agreements that address climate change effectively, and they do not yet address the intergenerational dimensions of climate change.

The Villach Article proposes a global strategy for climate change, which respects principles of intergenerational equity and a declaration as an initial step. Since then, UNESCO adopted in 1997 a Declaration on the Responsibilities of the Present Generations Toward Future Generations, which focuses on our obligations to future generations (but not their rights). At the end of March 2008, the Human Rights Council adopted a resolution on Human Rights and Climate Change, which requests the Office of the United Nations High Commissioner for Human Rights to conduct "a detailed analytical study of the relationship between climate change and human rights" for submission prior to the Council's tenth session. ${ }^{3}$

Climate change is expected to have the most harmful impacts on impoverished regions and communities, in part because they are most vulnerable to changes in climate and because they have the least capacity to adapt. Intergenerational equity and intragenerational equity are linked in this context. In the present generation, one cannot expect people to fulfill obligations to future generations if they are not able to satisfy their basic needs. As future generations become living generations, they inherit the intergenerational obligations to conserve options, quality, and access in relationship to other members of the present generation.

As reports have indicated, climate change is likely to produce profound effects on the way we live, now and in the future. The article written for the Villach Conference twenty years ago identifies some of the pressing issues in ensuring intergenerational equity. We can choose to leave an impoverished legacy to future generations and to increase the inequalities

3. Laura MacInnis, U.N. Human Rights Body Turns to Climate Change, ReUTERS, Mar. 28, 2008, http://www.reuters.com/article/environmentNews/idUSL2778449820080328. See generally U.N. Human Rights Council, Promotion and Protection of All Human Rights, Civil, Political, Economic, Social and Cultural Rights, Including the Right to Development, U.N. Doc. A/HRC/7/L.21/Rev.1 (Mar. 26,2008 ) (recognizing climate change as a threat to peoples and communities). 
among peoples today, or we can try to address the poverty issues today and to leave the Earth at least in no worse condition than we received it for future generations. If we have only obligations to future generations, we may act from a sense of noblesse oblige toward them. If, on the other hand, future generations have rights, people living today must consider their interests, examined from their perspective, in the actions we take today.

My congratulations to the Vermont Journal of Environmental Law and the Vermont Law Review for organizing this symposium on climate change and intergenerational equity and for contributing to an understanding of the issues.

Edith Brown Weiss, April 2008

APPENDIX D

CLIMATE CHANGE, INTERGENERATIONAL EQUTTY AND INTERNATIONAL LAW*

by Dr. Edith Brown Weiss

(Background Paper, Conference on Developing Policies for Responding to Future Climatic Change, Villach, Austria, 28 Sept.-2 Oct. 1987)

Global climate change induced partly by human activities raises serious issues of justice between the present generation and future generations, and between communities within future generations. In using the planet's resources for our own benefit, we may pass many of the costs to future generations in the form of climate change and the need to adapt to such change.

* The Vermont Journal of Environmental Law is reprinting Dr. Brown Weiss's Villach Article as it was originally published as Appendix D in IN FAIRNESS TO FUTURE GENERATIONS: INTERNATIONAL LAW, COMMON PATRIMONY, AND INTERGENERATIONAL EQUTTY 345-51 (1989). The footnotes below have not been modified to conform to THE BLUEBOOK: A UNIFORM SYSTEM OF CiTATION (Columbia Law Review Ass'n et al. eds., 18th ed. 2005). 
Traditionally people have attributed climate to God, other deities, or the vagaries of nature. At least until recently they have not attributed it to human activities. As a corollary they have not considered that they had any obligation to compensate others for harsh climate conditions. But this assumption may falter. It may now be possible at the planetary level to hold one generation responsible for triggering global climate changes for future generations. While it may still be impossible to pinpoint particular countries as responsible for specific climate changes, it is increasingly possible to identify the global cumulative effects of our activities on future climate. We can also identify certain kinds of activities, such as fossil fuel consumption, as contributing significantly to an increase in temperature.

We have certain obligations to future generations which must guide the strategies that we adopt to address issues of global climate change. Unless we recognize this, we will benefit ourselves at the expense of the welfare of future generations. We will also proceed on the unwritten assumption that we must do everything we can to preserve the status quo in climate and prevent change. But change may not necessarily be more harmful to future generations if we can take steps to ensure that the rate of change is slow, that direct damage from change is minimized, and that future generations receive the tools and resources with which to adapt to climate change.

As a first step in addressing our obligation to future generations, we need to identify potential problems of intergenerational equity, develop normative principles to guide us in addressing these problems, and translate these into specific policies and enforceable agreements.

\section{PROBLEMS OF INTERGENERATIONAL EQUITY}

Problems of equity arise both between the present generation (defined as people living today) and future generations, and between different communities within future generations. Some problems relate to the condition of the natural environment future generations will receive; others to the resources they will inherit for adapting to a changed natural environment.

\section{A. Changes in the Natural Environment}

Global climate change directly affects the natural environment, although the precise effects and distribution of these effects remains uncertain. If projected temperature increases occur, coastal areas will flood, precipitation patterns will shift, and weather fluctuations may become more frequent and extreme. Depending upon the rate of change, this may lead to 
degradation in the quality of the climate in major parts of the earth and decreased diversity in the natural resource base.

Degradation in the quality of the environment for future generations may arise at the global level and at regional and local levels. Many present centers of population may have climates that are regarded as less desirable than today. These will have significant societal impacts, such as population migrations and economic dislocations which can be costly for future generations. At the national level, coastlines may flood, causing members of future generations to abandon properties, to clean up polluted areas, and even to relocate urban areas. If coastlines flood in the future, the present generation will have reaped the benefits of coastal development and cheap waste disposal and inflicted potentially large costs on members of future generations.

Harsher climate conditions may also lead to depletion of the diversity of the natural resource base through the loss of existing species of flora and fauna unable to withstand the changes in temperature and precipitation or extreme fluctuations in weather. Advances in agriculture have led to the widespread adoption of crop strains which, while more productive, are also more vulnerable to climatic change. Many wild cultivars, useful in adapting to climate change, are being eliminated.

The depletion of the diversity of the natural resource base raises serious problems of equity for future generations because it narrows the range of options available to them in addressing their own problems and satisfying their needs.

Climate change will also raise significant equity concerns between communities within future generations because the changes will likely produce more favorable climates in a few parts of the world and less favorable in many others. Arguably those who will be better off should then help those who are worse off to share the burden. But those with relatively good climates today have been markedly reluctant to assist those with poorer climates, and such assistance as has been rendered, has not been viewed as compensatory for unfavorable climate conditions.

\section{B. Access to Resources for Adapting to Global Change}

The effects of global climate change upon the welfare of future generations depends upon the rate of climate change. The faster the rate, the heavier the costs are likely to be for future generations. While climate has always changed, the rate of change is unprecedented. While some of the changes in climate may objectively produce better conditions for human 
habitation in certain areas, all peoples will suffer unless they are able to adapt quickly and effectively to the changed conditions.

We may classify countries according to their level of economic development today and the climate conditions that are projected within the next century. The level of economic development can be used as a guide to a country's ability to adapt to changed climate conditions. The higher the level of economic development, the more likely it is that the country will have resources with which to adapt to global climate change.

The matrix outlined here yields, for simplicity, four basic groups: developed countries expecting possibly better climate conditions (such as Canada), developed countries expecting worse climate conditions (such as the United States and countries in Europe), developing countries expecting better climate conditions, and developing countries expecting worse climate conditions. Of these groups, those countries that are now poor and will suffer worse climate conditions in the future suffer the greatest burden from climate change, for they have the least capacity to adapt to climate change.

In terms of intergenerational equity, the matrix reveals that we can expect not only problems of equity between generations but serious problems of equity between members of any given future generation. In some instances, such as for those poor countries whose climate worsens, the burdens will exacerbate existing inequities in the international community. In other instances, such for those developing countries potentially receiving better climate conditions, the climatic inequities may be alleviated, but other inequities will not be unless the resources and skills for adapting to changed climate conditions are available and can be effectively utilized. Otherwise, climate change will strengthen the economic divisions which already exist between countries, since some countries will have a greater capacity to adapt than will others.

\section{THE THEORY OF INTERGENERATIONAL EQUITY}

Before developing strategies for managing global climate change, it is important to define our obligations to future generations. For this, we adopt the perspective of a generation which is placed somewhere on the spectrum of time, but does not know in advance where. ' Such a generation would want to receive the planet in at least as good condition as every other generation receives it and to be able to use it for its own benefit. This requires that each generation pass on the planet in no worse condition than

1. See J. Rawls, $A$ Theory of Justice (1971). 
received and have equitable access to its resources. From this we can formulate principles of intergenerational equity. As proposed in detail elsewhere, these principles would call for conservation of options (defined as conserving the diversity of the natural and cultural resources base), conservation of quality (defined as leaving the planet no worse off than received), and conservation of access (defined as equitable access to the use and benefits of the legacy). ${ }^{2}$

In the context of global climate change, implementation of these principles of intergenerational equity calls for measures to prevent rapid changes in climate, measures to prevent or mitigate damage from climate change, and measures to assist countries in adapting to climate change.

A strategy to prevent rapid climate change has been discussed by others. It includes such components as controlling the use of fuels rich in carbon, preventing deforestation and the misuse of soils, controlling the release of fluorochlorocarbons and other elements which destroy the ozone layer, and monitoring nitrogen fertilizer use. To fulfill our obligation to future generations, we need to evaluate these strategies against the normative goals of ensuring that our descendants have access to a planet with diversity and quality comparable to prior generations.

Strategies to minimize damage from anticipated climate change include many actions which we ought to take now for the welfare of our own and future generations, but which become more urgent in the face of global climate change. These include gathering and conserving germplasm for additional crops that are now neglected, and conserving the knowledge of traditional peoples of the utility of certain plants and animals, of ecosystems, and of practices adapted to harsh climate conditions. Many strategies to mitigate damage are appropriately implemented at the national and local levels. These include coastal zone management, particularly the siting of hazardous waste disposal facilities and nuclear power plants.

Strategies for adapting to climate change will involve research directed at anticipating changes, monitoring to detect changes, conservation of knowledge about how societies have adapted to climate changes in the past, development and maintenance of gene banks to assist in agricultural adaptations, planning for alternative water supplies, changes in land use, incentives to encourage or discourage population migrations as appropriate, and other measures. Some of these measures must be designed to assist

2. See, E. Brown Weiss, In Fairness to Future Generations: Intemational Law, Common Patrimony, and Intergenerational Equity (Transnational, 1989). See also E. Brown Weiss, "The Planetary Trust: Conservation and Intergenerational Equity," 11 Ecology L. Q. 295 (1984). 
communities during the transition stage to a new climate; others should have a longer-range focus.

Unless the present generation is willing to undertake such measures, it is reaping the benefits of its activities but passing the very substantial costs to future generations to bear.

\section{THE ROLE OF INTERNATIONAL LAW}

In order to implement a strategy for managing global climate change, it will be necessary to develop enforceable norms of behavior as the international, national, and local level.

International law, which dates to the early 17 th century and the rise of the sovereign nation-states, has been spatially oriented. To the extent that it considers the temporal dimension, it focuses mainly on the relationship of the present to the past. Problems of global climate change, which focus on the relationship of the present to the future, demand that it turn to the future. As set forth elsewhere, it would be useful to have a Declaration of the Planetary Rights and Obligations to Future Generations which would set forth principles of intergenerational equity to guide specific normative and policy developments in areas such as global climate change. ${ }^{3}$ As an initial step, such a Declaration could be drafted for the specific context of global climate change.

In developing a strategy for global climate change, there are already certain existing agreements which can be drawn upon to address specific aspects of the problem. Most of these agreements are intended to control pollution. They include the Vienna Convention for the Protection of the Ozone Layer, the Montreal Protocol on Substances that Deplete the Ozone Layer, the Economic Commission of Europe (ECE) Convention on LongRange Transboundary Air Pollution, the Protocol to reduce sulphur emissions by 30 percent, the draft Protocol on controlling nitrogen oxides, and the European Economic Community (EEC) directives and regulations on specific pollutants. ${ }^{4}$

3. See supra note 2; E Brown Weiss, "Intergenerational Justice and International Law," unpublished manuscript, presented to the Conference on Human Rights, Oxford University, May 1987.

4. Vienna Convention for the Protection of the Ozone Layer, March 22, 1985, 26 I.L.M. 1516 (1987); Montreal Protocol on Substances That Deplete the Ozone Layer, Sept. 1987, [Reference File] Int'l Env't Rep. (BNA) 21:3151; Convention on Long-Range Transboundary Air Pollution, Nov. 13, 1979, 18 I.L.M. 1440 (1979), T.I.A.S. No. 10541; Protocol on the Reduction of Sulphur Emissions or Their Transboundary Fluxes by At Least 30 Per Cent, July 6, 1985, [Reference File] Int'l Env't Rep. (BNA) 21:3021; Protocol on the Control of Emissions of Nitrogen Oxides (revised draft), 17 Envt'l 
Many countries have national legislation controlling the emission of air pollutants to various degrees, which could be extended to controlling emissions of chlorofluorocarbons, nitrous oxides, and perhaps carbon dioxide. Some countries have legislation mandating standards of energy efficiency (which cuts down on fuel or gasoline consumption) or providing incentives to use certain fuels rather than others. Such national legislation could be used to lower carbon dioxide emissions.

There are few international agreements to date which can be viewed as minimizing the direct effects of global climate change, such as coastal flooding and water contamination. International agreements controlling marine pollution offer useful precedents. These include the London Ocean Dumping Convention, the Law of the Sea Convention, the many regional seas conventions, and the recent convention controlling the disposal of wastes in the South Pacific. ${ }^{5}$ At the national level, some countries have enacted coastal zone management legislation, which could be useful in developing responses to projected coastal damage from global climate change. ${ }^{6}$ In the United States, state and local land use regulations play a critical role.

There are no international agreements to date directed to adapting to climate change. Those agreements providing for the monitoring and exchange of climate data are, of course, relevant to any adaptation strategy. Once there is agreement on what adaptation requires, however, international agreements to facilitate this policy will be needed.

\section{SCIENTIFIC UNCERTAINTY AND INTERNATIONAL LAW}

Planning for global climate change inherently involves large scientific uncertainties. As our understanding of how the climate system works, of how human activities affect the system, and of the impacts of global climate change upon the natural and cultural environment increases, it must be incorporated into our laws and institutions. In international law, this means

Pol'y \& L. 259 (1987); EEC Directive on Air Quality Standards for Nitrogen Dioxide, March 7, 1985, 28 O.J.Eur.Comm. 1 (1985).

5. Convention on the Prevention of Marine Pollution by Dumping of Wastes and Other Matter [London Ocean Dumping Convention], Dec. 29, 1972, T.I.A.S. No. 8165; U.N. Convention of the Law of the Sea, Dec. 10, 1982, 21 I.L.M. 1261 (1982); Convention for the Protection of the Natural Resources and Environment of the South Pacific Region, Nov. 25, 1986, 26 I.L.M. 38 (1987).

6. See U.S. Coastal Zone Management Act of 1972, 1985 ed. \& 1987 pocket. 16 U.S.C.A. 1451-64; Environmental Protection of Coastal Zone Management in Asia \& Pacific (I. Kato et. al. eds. 1986). 
drafting agreements in such a way that they can respond to changes in scientific knowledge.

There are several devices already in use in various international agreements for doing so, albeit they may not be adequate. One of the most common is the use of protocols and annexes to implement agreements and to regulate additional activities as scientific understanding advances. The Montreal Protocol on chlorofluorocarbons to the Vienna Convention on Protecting the Ozone Layer, the Protocol on sulphur emission and the draft Protocol on nitrogen oxides to the Convention on Long-Range Transboundary Air Pollution, the annexes to the Great Lakes Water Quality Agreement, the annex to the Convention on the Conservation of Antarctic Seals, and the protocols to many of the regional seas conventions, illustrate these. $^{\text {? }}$

International agreements have also used appendices or lists of regulated items effectively. In some instances the appendices set forth scientific criteria for placing items on the list. These agreements include the Great Lakes Water Quality Agreement between Canada and the United States, which lists hazardous and potentially hazardous pollutants in appendices, the London Ocean Dumping Convention, the Rhine Convention Against Pollution by Chlorides, the Convention on the Conservation of Migratory Species of Wild Animals, and the Convention on International Trade in Endangered Species of Wild Fauna and Flora. ${ }^{8}$

One of the most promising approaches is the use of scientific advisory boards which are established as part of the Conventions. These boards are usually authorized to advise on issues relevant to implementing the conventions. For example, the Migratory Species Scientific Council, attached to the Convention on the Conservation of Migratory Species of Wild Animals, is to provide scientific advice to the parties, recommend and evaluate relevant research, recommend migratory species for inclusion in

7. Montreal Protocol, supra note 4; Protocol on the Reduction of Sulphur Emissions, supra note 4; Protocol on the Control of Nitrogen Oxides, supra note 4; Great Lakes Water Quality Agreement, Nov. 22, 1978, T.I.A.S. No. 9257 and Protocol Amending the 1978 Agreement, signed Nov. 18, 1987; Convention on the Conservation of Antarctic Seals, June 1, 1972, T.I.A.S. No. 8826, and as an example of protocols to regional sea conventions, Protocol Concerning Cooperation in Combating Pollution of the Mediterranean Sea by Oil and Other Harmful Substances in Cases of Emergency, Feb. 16, 1967, 15 I.L.M. 306 (1976).

8. Great Lakes Water Quality Agreement, supra note 7; London Ocean Dumping Convention, supra note 5; Rhine Convention Against Pollution by Chlorides, Dec. 3, 1976, 16 I.L.M. 265 (1976); Convention on the Conservation of Migratory Species of Wild Animals, June 23, 1979 19 I.L.M. 11 (1976); Convention on International Trade in Endangered Species of Wild Fauna and Flora, March 3, 1979, T.I.A.S. No. 8249. 
the agreement, and suggest conservation measures. ${ }^{9}$ Similarly, the Great Lakes Water Quality Agreement establishes a Science Advisory Board to assist the Water Quality Board and members of the International Joint Commission, and ultimately the parties in implementing the Agreement. ${ }^{10}$ The Montreal Protocol on Substances That Deplete the Ozone Layer, the Convention on the Conservation of Antarctic Marine Living Resources, the Convention for the Conservation of Antarctic Seals, and the recent Convention on Antarctic Mineral Resources also provide for scientific advisory councils." In the context of global climate change, serious consideration should be given to include scientific advisory units in international agreements addressed to aspects of climate change.

\section{CONCLUSIONS}

We must recognize that global climate change caused in part by human activities raises serious problems of justice between our generation and future generations, and among communities within these future generations. To fulfill our responsibility to future generations we must respect principles of intergenerational equity. We need a Global Strategy for Climate Change, which reflects principles of intergenerational equity. The strategy should include measures to slow the rate of change, to minimize direct damage from change, and to transfer the resources and tools necessary to adapt to climate change. Elements of such a strategy must be translated into enforceable norms at the international, national, and local levels. As an initial step, we should consider a Declaration of Planetary Rights and Obligations addressed to issues of global change. Only by addressing issues of intergenerational equity now can we ensure that we are passing a planetary legacy to future generations which is no worse than we received it.

9. Art. VIII, Convention on Conservation of Migratory Species of Wild Animals, supra note 8.

10. Art. VIII, Great Lakes Water Quality Agreement, supra note 7.

11. Migratory Species Convention, supra note 8; Great Lakes Water Quality Agreement, supra note 7; Montreal Protocol, supra note 4; the Conservation of Antarctic Marine Living Resources, May 20, 1980, T.I.A.S. No. 10240; Convention for the Conservation of Antarctic Seals, June 1, 1972, supra note 7; Convention on the Regulation of Antarctic Mineral Resource Activities, June 2, 1988, 27 I.L.M. 859 (1988). 